\title{
Exogenous Arginine Enhances Antioxidant Defense System and Regulates the Physiology of Lentil (Lens culinaris) under Salt Stress ${ }^{+}$
}

\author{
Kamrun Nahar 1,*, Mirza Hasanuzzaman 2, Mazhar Ul Alam 3, Taufika Islam Anee 2, \\ Tasnim Farha Bhuiyan ${ }^{1}$ and Masayuki Fujita ${ }^{4}$ \\ 1 Department of Agricultural Botany, Faculty of Agriculture, Sher-e-Bangla Agricultural University, \\ Sher-e-Bangla Nagar, Dhaka-1207, Bangladesh; farhatasnim28@gmail.com \\ 2 Department of Agronomy, Faculty of Agriculture, Sher-e-Bangla Agricultural University, Sher-e-Bangla \\ Nagar, Dhaka-1207, Bangladesh; mhzsauag@yahoo.com (M.H.); taufiqaislam@gmail.com (T.I.A.) \\ 3 Independent Researcher; majharrony3511@gmail.com \\ 4 Laboratory of Plant Stress Response, Faculty of Agriculture, Kagawa University, Miki-cho, Kita-Gun, \\ Kagawa 761-0795, Japan; fujita@ag.kagawa-u.ac.jp \\ * Correspondence: knahar84@yahoo.com \\ + Presented at the 1st International Electronic Conference on Plant Science, 1-15 December 2020; Available \\ online: https://iecps2020.sciforum.net/.
}

Published: 3 December 2020

\begin{abstract}
Arginine (Arg) being one of the most important amino acids of plants involved in biosynthesis and induction of vital amino acid derivatives, enzymes, phytohormones and signaling molecules. The effect of exogenous Arg $(3.0 \mathrm{mM})$ was investigated in salt $(120$ and $150 \mathrm{mM} \mathrm{NaCl})$ treated lentil (Lens culinaris cv. BARI Mashur-2). Seven-day-old lentil seedlings were subjected to salt stress alone and in combination with Arg for $48 \mathrm{~h}$. Salt stress raised hydrogen peroxide (H2O2) content and membrane lipid peroxidation. Reduced ascorbate (AsA), increased glutathione disulfide (GSSG) content, decreased glutathione (GSH):GSSG together with altered activities of antioxidant enzymes caused the oxidative stress in salt affected plants. Salt stress decreased leaf relative water content (RWC) but increased proline (Pro) content. Chlorophyll (chl) a, b and total chl contents decreased under salt stress. Arginine co-treatment with salt stress decreased oxidative stress through improving AsA and GSH pool and activities of catalase, ascorbate peroxidase, monodehydroascorbate reductase, dehydroascorbate reductase and glutathione reductase. Decreased Pro level, improved RWC, chl content, growth parameters like plant height, root length and seedling dry weight in Arg supplemented salt affected plants are the indication of Arg-induced relaxation of salt stress and improved salt tolerance in lentil plants.
\end{abstract}

Keywords: abiotic stress; salinity; oxidative stress; reactive oxygen species; antioxidant defense system; amino acid; arginine

\section{Introduction}

Salinity is one of the major devastating abiotic stresses causing complex alteration in the physiology and biochemistry of plants. Salt stress primarily causes ionic stress immediate after exposure to the plant roots. Entering the plant salt stress causes ionic and nutritional imbalance and even toxicity. Decreased water uptake, stomatal conductance and decreased chlorophyll content can decrease photosynthesis which negatively affect the growth and developmental processes (Bendaly et al. 2016; Ahmed et al. 2020). Salt stress causes oxidative stress through generating reactive oxygen species (ROS). These ROS can cause oxidative damage to the cellular components. Plant nauturally beaing the antioxidant defense system capable of detoxifying certain amount of ROS. Beyond plants 
own antioxidant defense capacity if ROS over generate due to the effect of abiotic stress the ROS cause oxidative damage. The antioxidant defense system of plants is collection of ascorbate-glutathione (AsA-GSH) cycle comprising of two major non-enzymatic components: ascorbate (AsA) and glutathione (GSH) and four enzymes: ascorbate peroxidase (APX), monodehydroascorbate reductase (MDHAR), dehydroascorbate reductase (DHAR) and glutathione reductase (GR). Superoxide dismutase (SOD), catalase (CAT), and glutathione peroxidase (GPX) also play critical function in ROS detoxification (Nahar et al. 2016).

Arginine (Arg) is one of the most important among the available amino acids in plants. It is precursor of a range of amino acids derivatives including polyamines, agmatine, proline, glutamine and nitric oxide. Arginine metabolism is thus imperative not only in plant developmental processes but also in stress adaptation, defense or tolerance (Cottenie et al. 1982). There are very few studies those consider Arg as an stress protecting agent which may modulate plant physiology and biochemistry to improve stress tolerance. So, the present study investigates the role of Arg in modulating the physiology of lentil plants under salt stress. This study has special focus on the antioxidant defense mechanism of lentil plants.

\section{Experiments}

\subsection{Plant Materials, Growth Condition, and Stress Treatments}

Lentil (Lens culinaris cv. BARI Mashur-2) seedlings were grown in petri dishes under the conditions: light, $350 \mathrm{mmol}$ photon $\mathrm{m}^{-2} \mathrm{~s}^{-1}$; temperature, $25 \pm 2{ }^{\circ} \mathrm{C}$; relative humidity, $65-70 \%$; 10,000-fold diluted Hyponex solution (Hyponex, Japan) was applied as nutrient. Seven-day-old seedlings (three sets) were exposed to two levels of salt stress (120 and $150 \mathrm{mM} \mathrm{NaCl}$ ) alone and in combination with $\operatorname{Arg}(3.0 \mathrm{mM})$ for $48 \mathrm{~h}$. Control seedlings were grown with Hyponex solution.

\subsection{Lipid Peroxidation and $\mathrm{H}_{2} \mathrm{O}_{2}$ Content}

The level of lipid peroxidation was measured by estimating MDA using TBA according to Heath and Packer (1968) with modifications (Hasanuzzaman et al. 2011). Hydrogen peroxide $\left(\mathrm{H}_{2} \mathrm{O}_{2}\right)$ was assayed according to $\mathrm{Yu}$ et al. (2003).

\subsection{Extraction and Measurement of Ascorbate and Glutathione}

Ascorbate content was determined following the method of Hasanuzzaman et al. (2011). Total ascorbate was determined by the reduction of the oxidized fraction. Oxidized ascorbate (DHA) content was determined by subtracting reduced AsA from total AsA. The glutathione pool was assayed according to Hasanuzzaman et al. (2011). Standard curves with known concentrations of GSH and GSSG were used. The content of GSH was calculated by subtracting GSSG from total GSH.

\subsection{Leaf Relative Water Content}

Leaf relative water content (RWC) was measured according to Barrs and Weatherley (1962).

\subsection{Proline Content}

Proline (Pro) was calculated according to Bates et al. (1973) using 3\% sulphosalicyclic acid, acid ninhydrin, glacial acetic acid, phosphoric acid and toluene.

\subsection{Chlorophyll Content}

Chlorophyll (chl) $a, b$ and total chl contents were calculated according to Arnon (1949).

\subsection{Protein Determination and Enzyme Extraction and Assays}

The protein concentration was determined according to Bradford (1976). CAT (EC: 1.11.1.6) activity (Hasanuzzaman et al. 2011), APX (EC: 1.11.1.11) (Nakano and Asada 1981), MDHAR (EC: 
1.6.5.4) (Hossain et al. 1984), DHAR (EC: 1.8.5.1) (Nakano and Asada 1981) and GR (EC: 1.6.4.2) (Hasanuzzaman et al. 2011) activities were measured following standard methodologies.

\subsection{Determination of Growth Parameters}

Plant height and root length were measured from each set of seedlings. Ten randomly selected fresh seedlings from each treatment were dried at $80^{\circ} \mathrm{C}$ for $48 \mathrm{~h}$, then weighed and considered as seedling DW.

\section{Results}

\subsection{Oxidative Stress Indicators}

Hydrogen peroxide $\left(\mathrm{H}_{2} \mathrm{O}_{2}\right)$ is one of the major among the ROS which increased in salt affected lentil plants. In exposure to $\mathrm{S} 1$ and $\mathrm{S} 2$ the $\mathrm{H}_{2} \mathrm{O}_{2}$ increased significantly. Increase of membrane lipid peroxidation as indicated by increased MDA in also evident and proof of salt-induced oxidative damage. Arginine addition with salt treatment reverted the $\mathrm{H}_{2} \mathrm{O}_{2}$ generation and decreased lipid peroxidation (Figure 1).

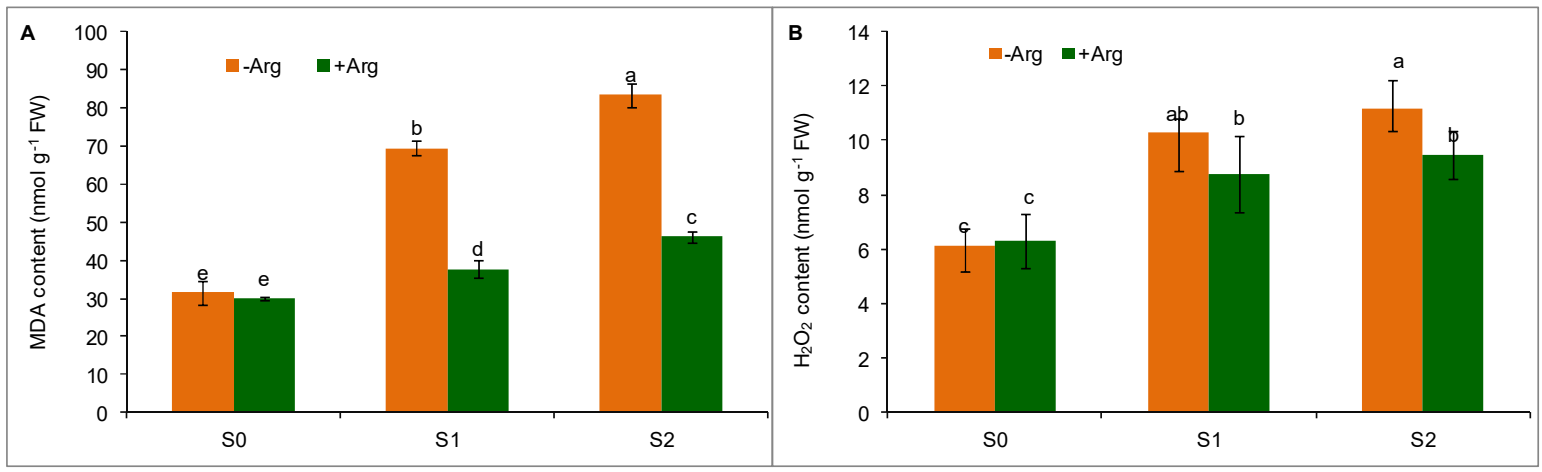

Figure 1. MDA (A) and $\mathrm{H}_{2} \mathrm{O}_{2}$ (B) contents in lentil induced by Arg under salt stress. Here Arg, $\mathrm{S} 1$ and S2 indicates $\operatorname{Arg}(3.0 \mathrm{mM}), 120$ and $150 \mathrm{mM} \mathrm{NaCl}$, respectively.

\subsection{Ascorbate and Glutathione Pool}

Ascorbate content decreased with the increase of salt stress, compared to control whereas it's content restored and increased with the supplementation of Arg in salt treatment (compared to salt stress alone).

An increase in GSH level was noticed under salt stress. The GSH level increased gradually due to S1 and S2 levels of salt (compared to control). Glutathione disulfide content also increased due to salt exposure. Increased GSH and decreased GSSG resulted a reduced GSH:GSSG in Arg added salt treatment, compared to salt treatment alone (Figure 2). 


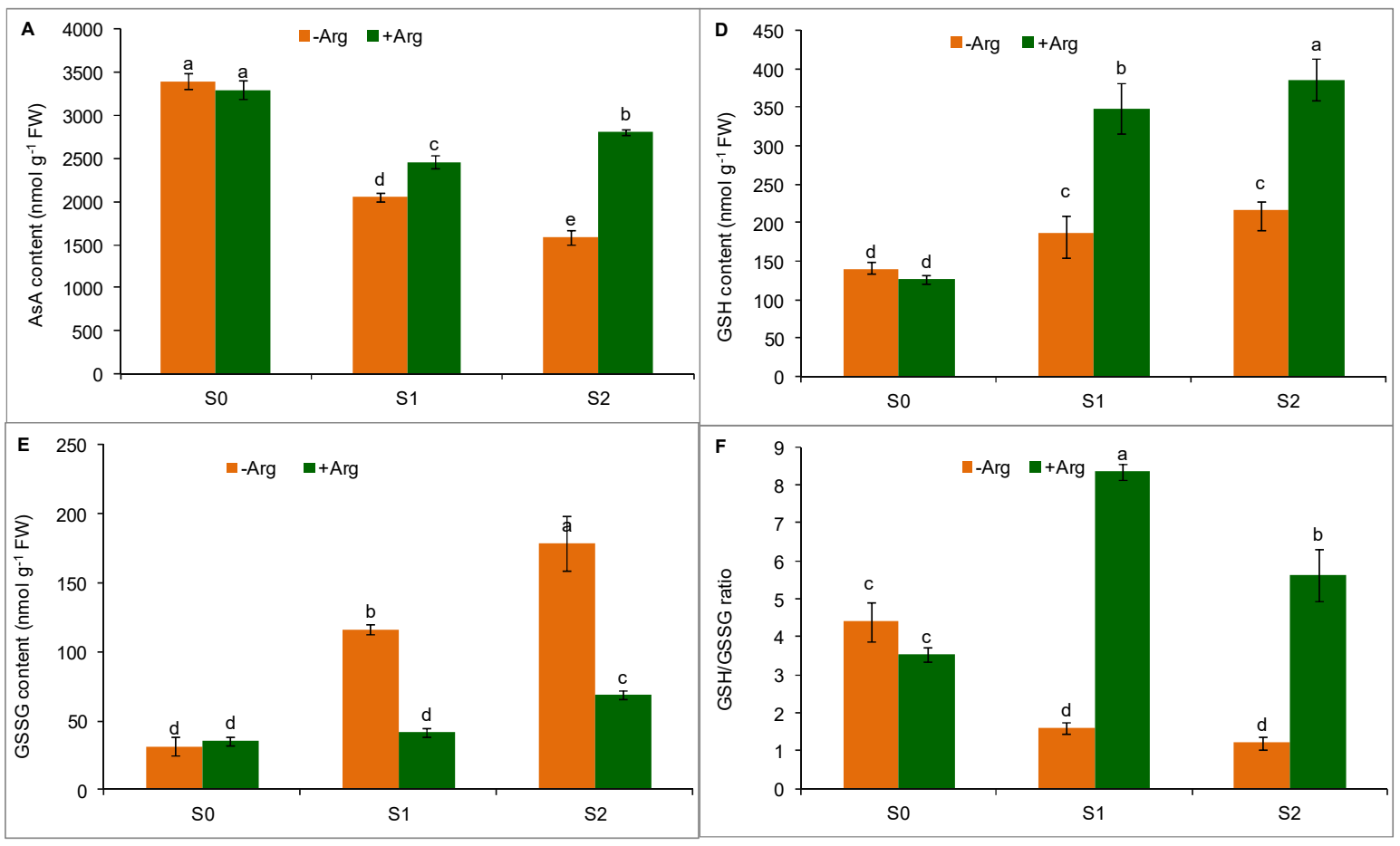

Figure 2. Contents of AsA (A), GSH (B) and GSSG (C); GSH:GSSG (D) in lentil induced by Arg under salt stress. Here Arg, S1 and S2 indicates Arg (3.0 mM), 120 and $150 \mathrm{mM} \mathrm{NaCl}$, respectively.

\subsection{Antioxidant Enzymes}

The activity of CAT decreased but the GPX activity increased under salt stress, compared to control.

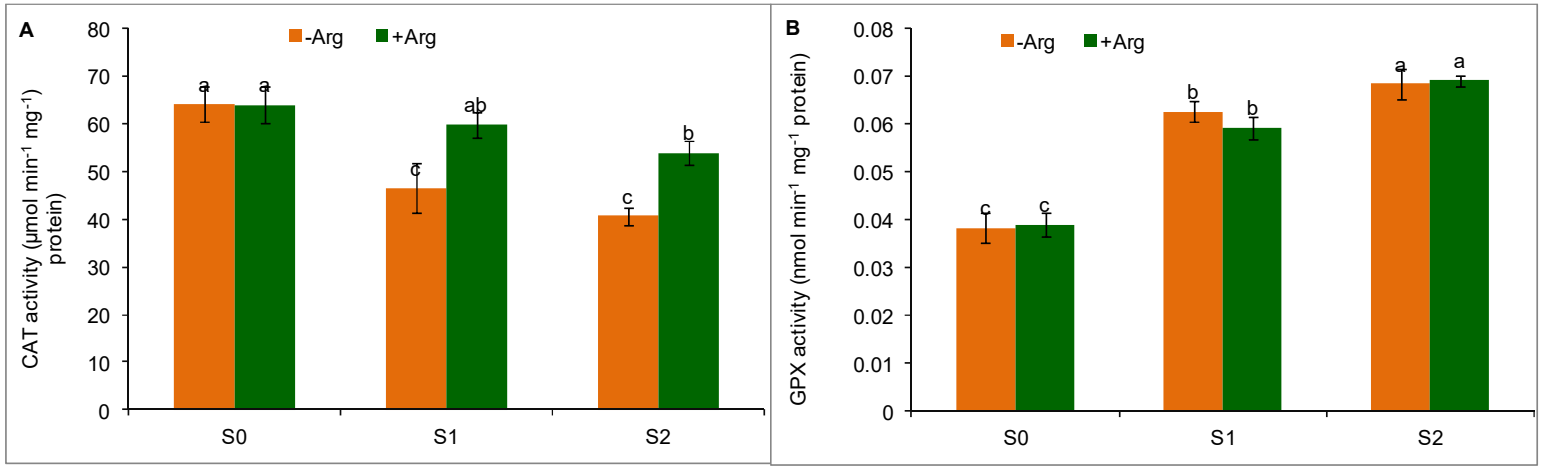

Figure 3. Activity of CAT (A) and GPX (B) in lentil induced by Arg under salt stress. Here Arg, S1 and S2 indicates $\mathrm{Arg}(3.0 \mathrm{mM}), 120$ and $150 \mathrm{mM} \mathrm{NaCl}$, respectively.

Among the enzymes of AsA-GSH cycle, APX and GR activity decreased but MDHAR and DHAR activity increased under salt stress, compared to control (Figure 4). 


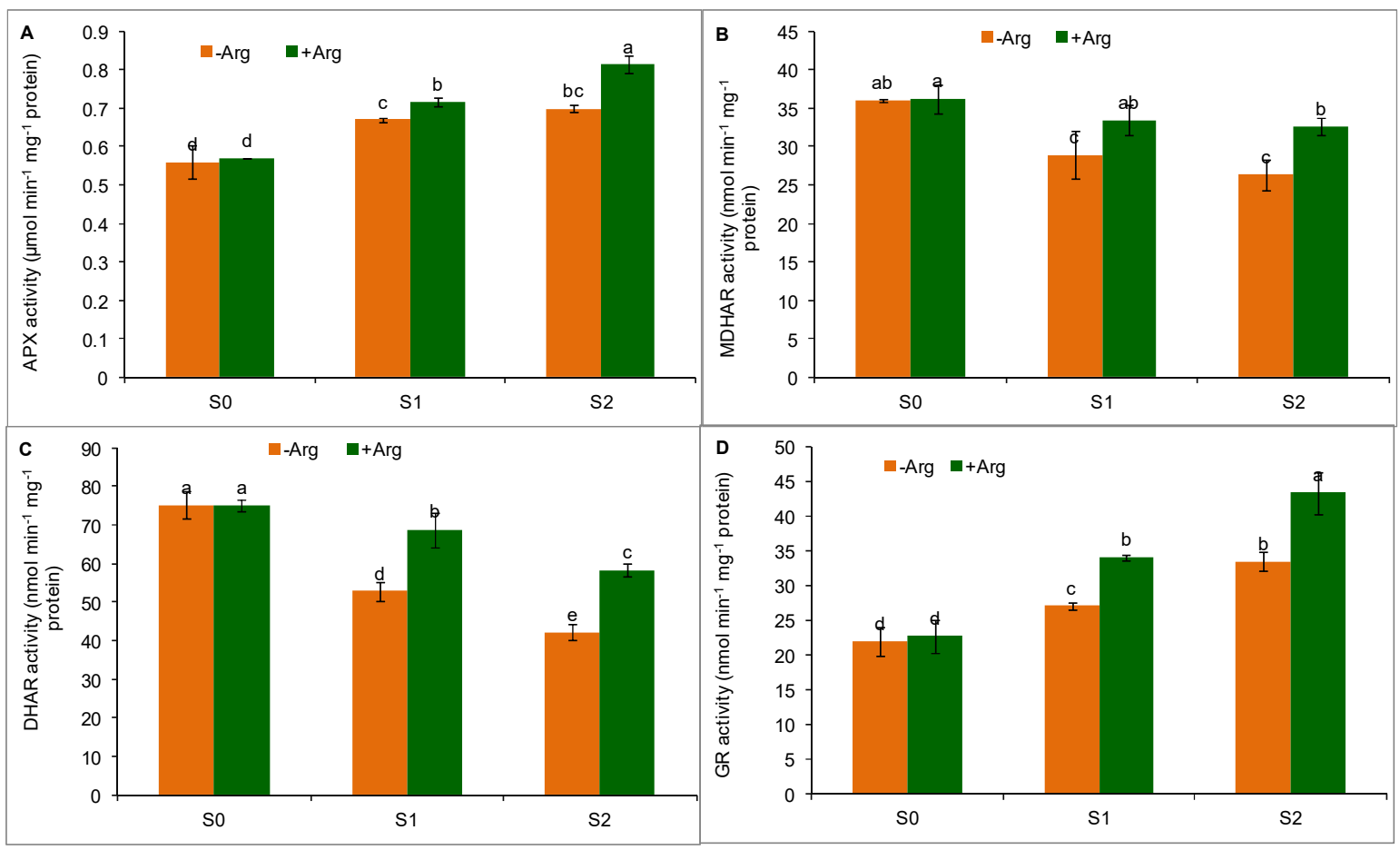

Figure 4. Activity of APX (A), MDHAR (B), DHAR (C) and GR (D) in lentil induced by Arg under salt stress. Here Arg, S1 and S2 indicates Arg (3.0 mM), 120 and $150 \mathrm{mM} \mathrm{NaCl}$, respectively.

Adding Arg with salinity the activities of antioxidant enzymes increased, compared to salt stress alone (Figure 4).

\subsection{Water Status and Pro Regulation}

Salt stress decreased leaf relative water content (RWC) but increased Pro content. Arginine addition with salt treatment decreased Pro level in S1 and S2 concentration of salinity (Table 1).

Table 1. Plant height, root length, leaf RWC, Pro content, chl $a, b$ and total chl $(a+b)$ contents in lentil seedings induced by Arg under salt stress.

\begin{tabular}{|c|c|c|c|c|c|c|c|}
\hline Treatment & $\begin{array}{c}\text { Root } \\
\text { Length } \\
\text { (cm) }\end{array}$ & $\begin{array}{l}\text { Dry Weight } \\
\text { Plant }^{-1}\end{array}$ & $\begin{array}{c}\text { Leaf RWC } \\
(\%)\end{array}$ & $\begin{array}{c}\text { Pro Content } \\
\left(\mu \mathrm{mol} \mathrm{g}{ }^{-1}\right. \\
\text { FW })\end{array}$ & $\begin{array}{c}\mathrm{Chl} a \\
\left(\mathrm{mg} \mathrm{g}^{-1} \mathrm{FW}\right)\end{array}$ & $\begin{array}{c}\mathrm{Chl} b \\
\left(\mathrm{mg} \mathrm{g}^{-1} \mathrm{FW}\right)\end{array}$ & $\begin{array}{c}\text { Total Chl } \\
(a+b) \\
\left(\mathrm{mg} \mathrm{g}^{-1} \text { FW) }\right.\end{array}$ \\
\hline Control & $9.80 \pm 0.10 \mathrm{a}$ & $0.025 \pm 0.001 \mathrm{a}$ & $95.87 \pm 2.53 a$ & $4.98 \pm 0.43 \mathrm{~d}$ & $0.47 \pm 0.015 b$ & $0.47 \pm 0.015 a$ & $0.94 \pm 0.030 \mathrm{a}$ \\
\hline Arg & $7.20 \pm 0.10 \mathrm{~d}$ & $0.019 \pm 0.001 \mathrm{bc}$ & $76.85 \pm 3.55 c$ & $12.14 \pm 0.69 \mathrm{~b}$ & $0.37 \pm 0.005 \mathrm{~d}$ & $0.33 \pm 0.002 c$ & $0.70 \pm 0.003 c$ \\
\hline S1 & $7.00 \pm 0.10 c$ & $0.018 \pm 0.001 \mathrm{c}$ & $71.40 \pm 0.73 d$ & $14.32 \pm 0.54 \mathrm{a}$ & $0.28 \pm 0.026 \mathrm{f}$ & $0.29 \pm 0.012 \mathrm{c}$ & $0.57 \pm 0.037 \mathrm{~d}$ \\
\hline S1+Arg & $9.70 \pm 0.10 \mathrm{a}$ & $0.026 \pm 0.001 \mathrm{a}$ & $94.70 \pm 0.66 a$ & $5.62 \pm 0.50 \mathrm{~d}$ & $0.50 \pm 0.005 a$ & $0.45 \pm 0.007 a$ & $0.95 \pm 0.012 \mathrm{a}$ \\
\hline S2 & $8.20 \pm 0.10 b$ & $0.022 \pm 0.001 \mathrm{~b}$ & $87.30 \pm 1.06 \mathrm{~b}$ & $9.37 \pm 0.73 c$ & $0.42 \pm 0.009 \mathrm{c}$ & $0.45 \pm 0.012 a$ & $0.88 \pm 0.021 \mathrm{~b}$ \\
\hline S2+Arg & $8.10 \pm 0.10 b$ & $0.021 \pm 0.001 \mathrm{~b}$ & $85.38 \pm 1.32 b$ & $11.79 \pm 0.92 \mathrm{~b}$ & $0.32 \pm 0.009 \mathrm{e}$ & $0.38 \pm 0.05 b$ & $0.71 \pm 0.059 c$ \\
\hline
\end{tabular}

\subsection{Photosynthetic Pigments}

Chlorophyll $a, b$ and total chl contents decreased due to S1 level of salt treatment. When S2 was applied chl a, b and total chl contents decreased was higher. Applying Arg with salt treated seedlings increased the levels of photosynthetic pigments, compared to salt treated seedlings without Arg (Table 1).

\subsection{Growth Parameters}

Growth parameters like plant height, root length and seedling dry weight decreased by salt imposition and contrarily increased by Arg supplementation with salt salt treatment which are the indication of Arg-induced relaxation of salt stress (Table 1). 


\section{Discussion}

Under salt stress, osmotic and ionic stress, nutritional imbalance, altered photosynthetic and ultrastructural organelles activity are responsible for ROS generation and oxidative stress (Bendaly et al. 2016; Akladious and Hanafy 2018; Ahmed et al. 2020). Lentil seedlings of the present study showed high $\mathrm{H}_{2} \mathrm{O}_{2}$ generation and MDA level which was reversed by the exogenous Arg addition with salt stress. This result is corroborating with previous research findings (Akladious and Hanafy 2018; Ahmed et al. 2020).

Lentil seedlings were not much efficient to sustain its non-enzymatic antioxidants' pool unders salt stress. Thus AsA and GSH levels were altered under salt stress which contributed to increase oxidative stress. Increased AsA and GSH contents as well as higher GSH:GSSG in Arg added salt treated plants indicating the influential role of Arg to enahnace the antioxidative capacity of lentil plants (Nahar et al. 2016; Rady et al. 2018).

The CAT and GPX are important for scavenging ROS. The enzymes of AsA-GSH cycle, detoxify toxic ROS in step by step process in an efficient way. Activities of antioxidant enzymes altered which caused the oxidative stress in salt affected plants. Altered enzymatic activity induced by salt stress was improved by Arg application which is supported by other's findings (Akladious and Hanafy 2018; Ahmed et al. 2020).

Salt stress increases the osmotic concentration of the plant growing media which imposes osmotic stress for plants. Increased Pro level together with decreased leaf RWC is the indication for osmotic stress by excess salt (Nahar et al. 2016). Arginine supplementation decreased the Pro level in salt affected plants which means the decrease of salt-induced osmotic stress (Akladious and Hanafy 2018; Ahmed et al. 2020).

Salt stress hampers the biosynthesis of photosynthetic pigment. Creating oxidative stress salt stress can damage the outer membrane of chloroplast or the membrane of thylakoid system. Break down of chlorophyll can be occurred under salt stress too. Increased levels of chl a, b and total chl in Arg supplemented salt treatment confirmed the protective effect of Arg under salt stress (Bendaly et al. 2016; Ahmed et al. 2020).

While studying the growth parameters of lentil plants under salt stress the plant height, root length and seedling dry weight showed decreasing pattern with the increase of salt levels. Salt-induced osmotic stress obstructs entrance of water in to the cell thus the cell expansion and cell division are hindered under salt stress which unfavorably affect the growth process. Decreased water uptake, stomatal conductance and decreased chlorophyll content can decrease photosynthesis which negatively affect the growth and developmental processes (Bendaly et al. 2016; Ahmed et al. 2020). In Arg supplemented salt affected plants the growth parameters were improved, compared to the salt stress alone. In the present study, Arg addition with salinity stress decreased osmotic stress, increased leaf RWC and levels of photosynthetic pigments which are correlated to the improved growth parameters supported by the results of previous research findings (Bendaly et al. 2016; Ahmed et al. 2020).

\section{Conclusions}

In the present study, lentil seedlings were adversely affected due to salt exposure in the growing media. Decreased leaf RWC and high rise of Pro indicated the osmotic stress and hindrance of water uptake due to salt exposure. Salt stress decreased the photosynthetic pigment levels. Altered antioxidant enzyme activities and the levels of non-enzymatic antioxidants resulted severe oxidative damage. Arginine supplementation with salt stress improving the antioxidant defense system alleviated oxidative stress. Arginine-induced osmoregulation, maintenance of water status, improvement of photosynthetic pigment levels, antioxidant defense system, reduction of oxidative damage were the clear evidence that prove the potential role of Arg. However, the long duration experiment, the age dependent experiment in different physiological and biochemical aspects are yet to reveal. 
Author Contributions: K.N.: M.H., and M.F. conceived and designed the experiments; K.N., M.U.A., T.I.A. and T.F.B. performed the experiments; M.H. analyzed the data; M.F. contributed reagents/materials/analysis tools; K.N. and T.I.A. wrote the manuscript. All authors read and approved the final manuscript. All authors have read and agreed to the published version of the manuscript.

Acknowledgments: The first author is grateful to the Ministry of Education, Culture, Sports, Science and Technology (MEXT), Japan for financial supports.

Conflicts of Interest: The authors declare no conflict of interest. The funding sponsors had no role in the design of the study; in the collection, analyses, or interpretation of data; in the writing of the manuscript, and in the decision to publish the results.

\section{Abbreviations}

The following abbreviations are used in this manuscript:

$\begin{array}{ll}\text { AO } & \text { ascorbate oxidase } \\ \text { APX } & \text { ascorbate peroxidase } \\ \text { AsA } & \text { ascorbic acid (ascorbate) } \\ \text { BSA } & \text { bovine serum albumin } \\ \text { CAT } & \text { catalase } \\ \text { Chl } & \text { chlorophyll } \\ \text { DHA } & \text { oxidized ascorbate } \\ \text { EDTA } & \text { ethylenediaminetetraacetic acid } \\ \text { GR } & \text { glutathione reductase } \\ \text { GSH } & \text { reduced glutathione } \\ \text { GSSG } & \text { oxidized glutathione } \\ \text { MDA } & \text { malondialdehyde } \\ \text { MDHA } & \text { monodehydroascorbate } \\ \text { MDHAR } & \text { monodehydroascorbate reductase } \\ \text { NADPH } & \text { nicotinamide adenine dinucleotide phosphate } \\ \text { Pro } & \text { Proline } \\ \text { ROS } & \text { reactive oxygen species } \\ \text { RWC } & \text { relative water content } \\ \text { SLG } & \text { S-D-actoylglutathione } \\ \text { TBA } & \text { thiobarbituric acid } \\ \text { TCA } & \text { trichloroacetic acid. }\end{array}$

\section{References}

1. Arnon, D.T. Copper enzymes in isolated chloroplasts polyphenal oxidase in Beta vulgaris. J. Plant Physiol. 1949, 24, 1-15, doi:10.1104/pp.24.1.1.

2. Barrs, H.D.; Weatherley, P.E. A re-examination of the relative turgidity technique for estimating water deficits in leaves. Aust. J. Biol. Sci. 1962, 15, 413-428, doi:10.1071/BI9620413.

3. Bates, L.S.; Waldren, R.P.; Teari, D. Rapid determination of free proline for water stress studies. Plant Soil 1973, 39, 205-207, doi:10.1007/BF00018060.

4. Bradford, M. A rapid and sensitive method for the quantitation of microgram quantities of protein utilizing the principle of protein-dye binding. Anal. Biochem. 1976, 72, 248-254, doi:10.1016/0003-2697(76)90527-3.

5. Hasanuzzaman, M.; Hossain, M.A.; Fujita, M. Nitric oxide modulates antioxidant defense and the methylglyoxal detoxification system and reduces salinity-induced damage of wheat seedlings. Plant Biotechnol. Rep. 2011, 5, 353-365, doi:10.1007/s11816-011-0189-9.

6. Heath, R.L.; Packer, L. Photoperoxidation in isolated chloroplast. I. Kinetics and stoichiometry of fatty acid peroxidation. Arch. Biochem. Biophys. 1968, 125, 189-198, doi:10.1016/0003-9861(68)90654-1.

7. Hossain, M.A.; Nakano, Y.; Asada, K. Monodehydroascorbate reductase in spinach chloroplasts and its participation in the regeneration of ascorbate for scavenging hydrogen peroxide. Plant Cell Physiol. 1984, 25, 385-395.

8. Nakano, Y.; Asada, K. Hydrogen peroxide is scavenged by ascorbate specific peroxidase in spinach chloroplasts. Plant Cell Physiol. 1981, 22, 867-880. 
9. Yu, C.W.; Murphy, T.M.; Lin, C.H. Hydrogen peroxide induces chilling tolerance in mung beans mediated through ABA-independent glutathione accumulation. Funct. Plant Biol. 2003, 30, 955-963, doi:10.1071/FP03091.

10. Nahar, K.; Hasanuzzaman, M.; Rahman, A.; Alam, M.M.; Mahmud, J.-A.; Suzuki, T.; Fujita, M. Polyamines confer salt tolerance in mung bean (Vigna radiata L.) by reducing sodium uptake, improving nutrient homeostasis, antioxidant defense, and methylglyoxal detoxification systems. Front. Plant Sci. 2016, 7, 1104, doi:10.3389/fpls.2016.01104.

11. Cottenie, A.; Verloo, M.;. Kiekens, L.; Velghe, G.; Camerlynck, R. Chemical Analysis of Plant and Soil; Laboratory of Analytical and Agrochemistry, State University Ghent: Gent, Belgium, 1982; pp. 100-129.

12. Akladious, S.A.; Hanafy, R.S. Alleviation of oxidative effects of salt stress in white lupine (Lupinus termis L.) plants by foliar treatment with L-arginine. J. Anim. Plant Sci. 2018, 28, 165-176.

13. Bendaly, A.; Messedi, D.; Smaoui, A.; Ksouri, R.; Bouchereau, A.; Abdelly, C. Physiological and leaf metabolome changes in the xerohalophyte species Atriplex halimus induced by salinity. Plant Physiol. Biochem. 2016, 103, 208-218.

14. Ahmed, A.M.A.; El-Gohary, A.E.; Osman, S.A.; Khalid, A.K. Arginine and salinity stress affect morphology and metabolism of Indian borage (Plectranthus amboinicus lour.). Acta Ecol. Sin. 2020, 40, 417-424.

15. Badi, H.N.; Mehrafarin, A.; Mustafavi, S.H.; Labbafi, M. Exogenous arginine improved fenugreek sprouts growth and trigonelline production under salinity condition. Indus. Crop. Prod. 2018, 122, 609-616.

16. Rady, M.O.; Semida, W.M.; El-Mageed, T.A.A.; Hemida, K.A.; Rady, M.M. Up-regulation of antioxidative defense systems by glycine betaine foliar application in onion plants confer tolerance to salinity stress. Sci. Hortic. 2018, 240, 614-622.

Publisher's Note: MDPI stays neutral with regard to jurisdictional claims in published maps and institutional affiliations.

(C) 2020 by the authors; licensee MDPI, Basel, Switzerland. This article is an open access article distributed under the terms and conditions of the Creative Commons by Attribution (CC-BY) license (http://creativecommons.org/licenses/by/4.0/). 